\title{
ANALISIS MODAL POLITIK, SOSIAL, DAN EKONOMI TERHADAP KETERPILIHAN CALEG PEREMPUAN PEMULA PADA PILEG DPRD DKI JAKARTA 2019
}

\author{
Giscka Canna Indira S ${ }^{(1)}$, Chusnul Mariyah ${ }^{(2)}$ \\ ${ }^{(1)(2)}$ Departemen Ilmu Politik Universitas Indonesia, Jl.Margonda Raya, Kota Depok, Jawa Barat \\ ${ }^{(1)}$ Corresponding Author: gisckacanna@gmail.com
}

\begin{abstract}
Abstrak: Keterpilihan perempuan sebagai anggota legislatif di DKI Jakarta masih relatif rendah dengan keterpilihan dibawah 30\% kursi yang diperebutkan pada pemilu legislatif dari tahun 20042019. Sebagai daerah yang menjadi barometer politik nasional, hal ini menjadi penting untuk diteliti. Artikel ini menganalisis bagaimana calon legislatif perempuan pemula dapat terpilih menjadi anggota legislatif dengan pendekatan modal politik, modal sosial, dan modal ekonomi. Ketiga pendekatan ini diambil karena Jakarta merupakan wilayah yang dinamis secara politik, majemuk secara sosial, dan berpengaruh secara ekonomi. Artikel ini menggunakan metode kualitatif dengan pengambilan data melalui wawancara mendalam terhadap salah satu calon legislatif pemula terpilih. Berdasarkan pendekatan dan metodologi yang diambil, modal politik, sosial, dan ekonomi berpengaruh terhadap keterpilihan calon legislatif perempuan pemula. Penguasaan modal politik dan sosial dapat disimpulkan lebih berpengaruh terhadap keterpilihan calon legislatif perempuan pemula, namun penguasaan modal ekonomi merupakan penguat dari modal politik dan sosial. Disamping itu, modal ekonomi erat keterkaitannya dengan aspek-aspek praktis kampanye seperti pendanaan untuk materi kampanye, kampanye tatap muka, dan insentif bagi tim kampanye dan saksi.
\end{abstract}

Kata Kunci: Calon Legislatif Perempuan Pemula; Modal Politik; Modal Sosial; Modal Ekonomi.

Abstract: From 2004 to 2019, for more than a decade, the participation of females as members of the regional parliament of DKI Jakarta (Special Capital Region of Jakarta) is relatively low compared to the desired number of 30\%. The position of Jakarta as a barometer of Indonesian national politics makes this phenomenon relevant to be examined. This article analyses how first-time female legislative candidates could be elected to be the member of the Jakarta House of Representatives, using social, political, and economic capital approaches. In addition, this article uses a qualitative method by an indepth interview with one of the elected first-time female legislative candidates. The control over these types of capital affects the electability of a legislative candidate. Social and political capital has more significance compared to economic capital in affecting the election outcome, but the control of economic capital has a role to strengthen political and social capital. In addition, economic capital has strong connections to practical aspects of an election campaign, especially to fund campaign materials, town hall meetings, and financial incentives for campaign teams and vote count witnesses.

Keywords: First-time Female Legislative Candidates, Political Capital, Social Capital, Economic Capital

Article History:

Received 03 April 2021; Revised 23 April 2021; Accepted 25 Juni 2021 


\section{PENDAHULUAN}

Keterwakilan perempuan dalam politik merupakan salah satu poin penting dalam demokrasi. Secara historis, partisipasi politik perempuan di Indonesia diketahui sangat rendah selama tiga dekade periode Orde Baru (1967-1998) baik di tingkat nasional maupun daerah (Robinson, 2000). Namun, sejak pemilu tahun 2004, Indonesia telah menerapkan kebijakan kuota 30\% untuk perempuan baik dalam pemilu legislatif maupun dalam kepengurusan partai politik melalui UU No. 12 tahun 2003. Kebijakan kuota tersebut bertujuan untuk merekrut kaum perempuan ke dalam dunia politik dan diupayakan dapat menduduki kursi-kursi legislatif, sehingga kaum perempuan diharapkan mempunyai hak suara di dalam menentukan kebijakan-kebijakan pemerintahan yang ada.

Menurut Judith Squires (1999) ada tiga alasan mengapa kuota perempuan di parlemen merupakan hal yang penting penting, (1) kuota akan menciptakan adanya women agency yang dapat menjadi perpanjangan tangan perempuan dalam menyuarakan dan memperjuangkan regulasi yang sensitif gender pada arena pengambil kebijakan, (2) kuota perempuan akan memastikan adanya kebijakan adil terhadap gender untuk memastikan bahwa prinsip-prinsip mainstreaming gender di integrasikan dalam tiap tahapan pengambilan kebijakan, (3) kuota perempuan dapat menyasar pada peningkatan kuantitas jumlah perempuan di berbagai institusi pengambilan keputusan secara singkat sebagai tindakan khusus sementara (affirmative action).

Penerapan undang-undang kuota $30 \%$ terhadap perempuan menunjukkan adanya pencapaian keterwakilan perempuan di legislatif. Pada pemilu legislatif tahun 2019, perolehan kursi perempuan di DPR RI sejumlah 118 kursi (20,52\%). Jumlah tersebut merupakan perolehan kursi perempuan terbanyak di DPR RI dari periode-periode sebelumnya. Kemudian di DPD RI jumlah kursi perempuan pada periode 2019-2024 juga mencapai 30\%, yakni sejumlah 42 kursi (30,88\%). Selain itu, keterwakilan perempuan di DPRD juga menunjukan kenaikan perolehan kursi perempuan pada pemilu legislatif tahun 2019. Meskipun perolehan kursi perempuan semakin meningkat dari periode ke periode, jumlah tersebut belum setara dengan perolehan kursi laki-laki.

Seperti pada pemilu legislatif Provinsi DKI Jakarta tahun 2019, keterpilihan perempuan mengalami kenaikan sebesar 3,78\% dari periode sebelumnya, yakni dengan persentase sebesar 21,70\% atau sejumlah 23 kursi dari total 106 kursi. Namun, jika melihat kemenangan yang raih oleh calon legislatif perempuan terpilih dalam pemilu legislatif DPRD Provinsi DKI Jakarta tahun 2019, beberapa diantaranya merupakan calon legislatif perempuan pemula yang belum pernah mengikuti pemilu legislatif dan rata-rata masih berusia 20-30 tahun. Jika dibandingkan dengan calon legislatif perempuan petahana yang sudah memiliki pengalaman di DPRD Provinsi DKI Jakarta, calon legislatif perempuan pemula yang terpilih terbilang memiliki pengalaman politik yang minim. Calon legislatif perempuan pemula yang terpilih, rata-rata sebelumnya tidak berkecimpung di politik dan baru masuk partai politik. Jika dilihat dari profil calon legislatif perempuan terpilih di lembaga legislatif, banyak perempuan yang memiliki latar belakang public figure, selebritis, atau memiliki hubungan keluarga/kekerabatan dengan pejabat politik/penguasa (Venatius, 2015).

Dalam pemilu legislatif, perempuan memiliki kapabilitas dan figur yang cenderung rendah (Mutmainnah, 2017). Hal tersebut menjadi keterbatasan bagi perempuan untuk mengasosiasikan program-program mereka dalam mendapatkan suara dari pemilih. Selain itu, adanya ketimpangan gender membuat perempuan termarjinalkan di lembaga politik. Meskipun demikian, perempuan memiliki kesempatan untuk dipilih. Terlebih bagi calon legislatif perempuan yang baru pertama kali mengikuti pemilu legislatif. Sebagai pemain baru dalam pemilihan legislatif, calon legislatif perempuan pemula harus memiliki kemampuan dan pemahaman. Selain itu, dalam pemilihan legislatif, modal politik (political capital), modal sosial (social capital) dan modal ekonomi (economic capital) dapat mempengaruhi seorang kandidat politik dalam memperoleh dukungan yang kuat dari masyarakat (Sirait, Noak, Azhar: 2020).

Beberapa penelitian terdahulu terkait modal politik (political capital), modal sosial (social capital) dan modal ekonomi (economic capital) dalam pemilu, menunjukan pentingnya ketiga modal tersebut dalam kemenangan calon legislatif perempuan dalam pemilu legislatif. Seperti penelitian yang dilakukan oleh Nurmalasari (2010) tentang modalitas perempuan dalam kontestasi politik lokal (studi kasus pada calon legislatif perempuan dalam pemilu legislatif tahun 2009 di Kabupaten Indramayu), hasil penelitiannya menunjukkan bahwa calon legislatif perempuan memanfaatkan relasi yang dimiliki oleh orang-orang terdekatnya. Kemudian, penelitian lain yang terkait juga dilakukan oleh Sirait, dkk (2020) tentang modalitas dalam keterpilihan kandidat pada pemilu legislatif 2014 menunjukan bahwa 
modalitas berupa modal politik, modal sosial, dan modal ekonomi dapat menentukan keberhasilan seseorang dalam pemilu legislatif.

Pada penelitian ini, dari 23 calon legislatif perempuan yang terpilih pada pemilu legislatif DPRD Provinsi DKI Jakarta tahun 2019, akan difokuskan pada calon legislatif perempuan pemula yang berhasil memenangkan pemilu legislatif untuk pertama kalinya. Hal ini dimaksudkan untuk dapat menjelaskan modal-modal yang dimiliki oleh calon legislatif perempuan pemula untuk dapat terpilih pada pemilu legislatif DPRD Provinsi DKI Jakarta tahun 2019. Modal-modal yang dimiliki calon legislatif perempuan pemula terpilih tentu berbeda dengan calon legislatif petahana terpilih. Seorang petahana dianggap memiliki peluang yang lebih besar dari pada para kandidat lainnya, karena dianggap telah memiliki modal lebih seperti tingkat popularitas dan figuritas (Baharuddin dan Purwaningsih, 2017). Sedangkan calon legislatif perempuan pemula yang berhasil memenangkan pemilu legislatif untuk pertama kalinya, menarik untuk dikaji terkait modal-modal yang dimilikinya.

\section{METODE PENELITIAN}

Metode penelitian yang digunakan dalam penelitian ini adalah metode kualitatif. Hal ini bertujuan untuk memahami fenomena tentang apa yang dialami oleh subjek penelitian misalnya perilaku, cara deskripsi dalam bentuk kata-kata dan bahasa, pada suatu konteks khusus yang alamiah dan dengan memanfaatkan berbagai metode alamiah (Moleong, 2012). Penelitian ini dilakukan di wilayah Provinsi DKI Jakarta dengan subyek penelitian modal politik, modal sosial, dan modal ekonomi calon legislatif perempuan pemula yang terpilih dalam pemilu legislatif DPRD Provinsi DKI Jakarta tahun 2019. Adapun narasumber dalam penelitian ini adalah calon legislatif perempuan pemula terpilih pada pemilu legislatif DPRD Provinsi DKI Jakarta tahun 2019. Sedangkan jenis data yang digunakan adalah data primer yang diperoleh melalui wawancara mendalam dengan narasumber dan data sekunder yang diperoleh dari studi literatur yang dapat membantu penulis untuk menguatkan argumen dalam artikel ini, seperti: dokumen pemerintah, hasil riset sebelumnya yang terkait dengan topik dan pemberitaan media massa online.

\section{HASIL DAN PEMBAHASAN}

\section{Perolehan Kursi Perempuan Pada Pemilu Legislatif DPRD Provinsi DKI Jakarta tahun 2019}

Pelaksanaan pemilu legislatif DPRD Provinsi DKI Jakarta tahun 2019 dilaksanakan pada tanggal 17 April 2019. Pada pelaksanaannya, terdapat 106 kursi DPRD dan terdapat 10 dapil yang diperebutkan. Berdasarkan hasil penetapan suara dan kursi yang didapat di DPRD Provinsi DKI Jakarta untuk periode 2019-2024, PDIP mendapatkan kursi terbanyak yakni sejumlah 25 kursi. Kemudian diikuti Partai Gerindra 19 kursi, PKS 18 kursi, Partai Demokrat 10 kursi, PAN 19 kursi, PSI 8 kursi, Partai Nasdem 7 kursi, PKB 5 kursi, Partai Golkar 6 kursi, dan PPP 1 kursi. Sementara itu, enam partai lain yakni Perindo, Partai Berkarya, Partai Hanura, PBB, Partai Garuda dan PKPI tidak mendapatkan kursi di DPRD DKI Jakarta. Berikut ini adalah jumlah perolehan suara dan kursi partai-partai pada pemilu legislatif DPRD DKI Jakarta tahun 2019.

Dari total 106 kursi yang diperoleh partai-partai pemenang pemilu legislatif DPRD Provinsi DKI Jakarta tahun 2019, terdapat 23 kursi $(21,07 \%)$ yang berhasil diperoleh calon legislatif perempuan. Dari total 23 kursi yang berhasil diraih oleh calon legislatif perempuan, PDIP mendapatkan kursi paling banyak, yaitu sejumlah 11 kursi (44\%), kemudian disusul Partai Gerindra sejumlah 2 kursi (10,53\%), PKS sejumlah 3 kursi (18,75\%), Partai Demokrat sejumlah 4 kursi (40\%), PAN sejumlah 1 kursi (11,11\%), dan PSI sejumlah 2 kursi (25\%). Partai-partai yang tidak memiliki wakil calon legislatif perempuan terpilih adalah Partai Nasdem, Partai Golkar, PKB dan PPP. Jumlah tersebut merupakan perolehan kursi perempuan terbanyak dibandingkan pemilu legislatif DPRD Provinsi DKI Jakarta pada periode-periode sebelumnya. Berikut ini adalah tabel perolehan suara dan kursi pada pemilu legislatif DPRD Provinsi DKI Jakarta tahun 2019. 
Tabel 1. Hasil Perolehan Suara dan Kursi pada Pemilu Legislatif tahun 2019

\begin{tabular}{|l|c|c|c|}
\hline \multicolumn{1}{|c|}{ NAMA PARTAI } & $\begin{array}{c}\text { PEROLEHAN } \\
\text { SUARA }\end{array}$ & $\begin{array}{c}\text { TOTAL } \\
\text { PEROLEHAN } \\
\text { KURSI }\end{array}$ & $\begin{array}{c}\text { PEROLEHAN } \\
\text { KURSI } \\
\text { PEREMPUAN }\end{array}$ \\
\hline PDIP & 1.336 .344 & 25 & 11 \\
\hline PARTAI GERINDRA & 935.793 & 19 & 2 \\
\hline PKS & 917.005 & 16 & 4 \\
\hline PARTAI DEMOKRAT & 386.434 & 10 & 1 \\
\hline PAN & 375.882 & 9 & 2 \\
\hline PSI & 404.508 & 8 & 0 \\
\hline PARTAI NASDEM & 309.790 & 7 & 0 \\
\hline PKB & 308.212 & 5 & 0 \\
\hline PARTAI GOLKAR & 300.246 & 6 & - \\
\hline PPP & 175.935 & 1 & - \\
\hline PARTAI PERINDO & 168.296 & - & - \\
\hline PARTAI BERKARYA & 119.690 & - & - \\
\hline PARTAI HANURA & 103.073 & - & - \\
\hline PARTAI GARUDA & 19.205 & - & - \\
\hline PKPI & 15.765 & - & 0 \\
\hline
\end{tabular}

Sumber: KPU RI, 2021. Diolah oleh peneliti

Pada pemilu legislatif tahun 2004, perolehan kursi perempuan di DPRD Provinsi DKI Jakarta hanya sejumlah 11 kursi $(14,67 \%)$. Kemudian, pada pemilu legislatif tahun 2009 perolehan kursi oleh perempuan mengalami kenaikan sebesar 50\% atau dengan jumlah perolehan kursi sejumlah 22 kursi $(23,40 \%)$. Sedangkan pada pemilu legislatif tahun 2014, perolehan kursi perempuan sejumlah 19 kursi (17,92\%). Jumlah tersebut menunjukan bahwa dalam pelaksanaan pemilu legislatif DPRD Provinsi DKI Jakarta dalam empat periode (2004, 2009, 2014, dan 2019) selalu tidak memenuhi ketetapan 30\% kursi perempuan, bahkan perbandingan pada tahun 2009 dengan 2014 mengalami penurunan sebesar 5,48\% dan mengalami kenaikan kembali pada pemilu legislatif tahun 2019 sebesar 3,8\%.

Tabel 2. Perolehan Kursi Perempuan di DPRD Provinsi DKI Jakarta

\begin{tabular}{|c|c|c|c|c|c|}
\hline \multirow{2}{*}{ Tahun } & \multicolumn{3}{|c|}{ Jumlah Kursi } & \multicolumn{2}{c|}{ Persentase Kursi } \\
\cline { 2 - 6 } & Total & Perempuan & Laki-Laki & Perempuan & Laki-Laki \\
\hline 2004 & 75 & 11 & 64 & $14,67 \%$ & $85,33 \%$ \\
\hline 2009 & 94 & 22 & 72 & $23,40 \%$ & $76,60 \%$ \\
\hline 2014 & 106 & 19 & 87 & $17,92 \%$ & $82,08 \%$ \\
\hline 2019 & 106 & 23 & 83 & $21,70 \%$ & $78,30 \%$ \\
\hline
\end{tabular}

Sumber: KPU Provinsi DKI Jakarta. Diolah oleh peneliti

Calon legislatif perempuan yang berhasil terpilih pada pemilihan legislatif DPRD Provinsi DKI Jakarta tahun 2019 sebanyak 23 orang yang terdiri dari: Wa Ode Herlina (PDIP), Agustina Hermanto (PDIP), Ida Mahmudah (PDIP), Yuke Yurike (PDIP), Lauw Siegvrieda (PDIP), Cinta Mega (PDIP), Ong Yenny (PDIP), Merry Hotma (PDIP), Ima Mahdiah (PDIP), Stephanie Octavia (PDIP), Esti Arimi Putri (Gerindra), Rani Mauliani (Gerindra), Yusriah Dzinnun (PKS), Umi Kalsum (PKS), Solikhah (PKS), Desie Christhyana Sari (Demokrat), Neneng Hasanah (Demokrat), Nur Afni Sajim (Demokrat), Wita Susilowaty (Demokrat), Zita Anjani (PAN), Viani Limardi (PSI), Eneng Maliyanasari (PSI). Dari 23 calon legislatif perempuan terpilih tersebut, terdapat calon legislatif perempuan pemula yang baru pertama kali mengikuti pemilu dan berhasil memenangkan kursi di DPRD Provinsi DKI Jakarta pada pemilu legislatif tahun 2019. 


\section{Profil Calon Legislatif Perempuan Pemula}

Calon legislatif perempuan pemula adalah calon legislatif perempuan yang baru pertama kali mengikuti pemilihan legislatif dan berhasil memenangkan pemilu legislatif. Pada Pemilu Legislatif DPRD Provinsi DKI Jakarta tahun 2019, terdapat sebelas calon legislatif perempuan pemula. Para calon legislatif perempuan pemula ini diusung oleh beberapa partai politik, yaitu PDIP (Ima Mahdiah, Wa Ode Herlina, Agustina Hermanto, dan Stephanie Octavia), Gerindra (Esti Arimi Putri), Demokrat (Desie Christhyana Sari dan Wita Susilowaty), PAN (Zita Anjani), PSI (Viani Limardi dan Eneng Maliyanasari). Para calon ini datang dari latar belakang pengurus partai, aktivis, pengusaha, dan figur publik.

Salah satu calon yang menjadi objek penelitian adalah Ima Mahdiah yang diusung oleh PDIP. Ima mengawali karir sebagai staf khusus Gubernur DKI Jakarta periode 2014-2017, Basuki Tjahaja Purnama. Selama menjadi staf khusus Gubernur DKI Jakarta, Ima ditugaskan Basuki untuk menangani pengaduan masyarakat di bidang kesehatan. Disamping itu, Ima juga menjadi tim sukses Basuki untuk Pilkada DKI Jakarta tahun 2017. Pada tahun 2018, Ima bergabung ke PDIP, mengikuti Basuki yang telah bergabung sebelumya.

Di tahun yang sama, Ima bersiap maju sebagai calon legislatif DPRD DKI Jakarta untuk pemilu legislatif tahun 2019 untuk daerah pemilihan DKI Jakarta X yang meliputi wilayah Kota Administrasi Jakarta Barat (Kec. Taman Sari, Kec. Grogol Petamburan, Kec. Palmerah, Kec. Kebon Jeruk, Kec. Kembangan). Selama masa kampanye Ima menjaring pemilih melalui aktivitas sosial kemasyarakatan, termasuk kunjungan ke rumah-rumah warga dan kampanye terbuka. Ia juga memanfaatkan figur Basuki yang memang memiliki basis pendukung di daerah pemilihan DKI Jakarta X. Ima sering menyertakan foto dan profil Basuki pada media kampanye yang ia gunakan. Selain itu, Ima juga sering menyebutkan dirinya sebagai staf Basuki, sehingga menambah kredibilitasnya selama kampanye.

Berdasarkan hasil rekapitulasi suara KPU Provinsi DKI Jakarta, Ima Mahdiah memperoleh 30.591 suara dan dinyatakan memenangkan pemilu legislatif tahun 2019. Jumlah suara tersebut merupakan perolehan suara tertinggi dibandingkan para calon legislatif PDIP lainnya di dapil DKI Jakarta X. Dalam wawancara dengan peneliti, Ima menyatakan bahwa keterkaitan dirinya dengan figur Basuki dan seringnya ia turun ke masyarakat merupakan faktor yang mempengaruhi pencapaian dirinya di pemilu legislatif DPRD DKI Jakarta tahun 2019 (Wawancara, 8 Februari 2021).

\section{Analisis Modal Politik, Modal Sosial, dan Modal Ekonomi}

Keterpilihan Ima Mahdiah, baik sebagai calon legislatif perempuan pemula maupun sebagai peraih suara terbesar di dapil DKI Jakarta X merupakan fenomena yang perlu diteliti secara lebih mendalam. Keterpilihan Ima merupakan fenomena yang unik di dunia politik Indonesia maupun DKI Jakarta, dimana seseorang yang bukan pengurus teras partai (baik di pengurus pusat maupun di pengurus daerah), bukan pengusaha nasional, dan bukan laki-laki dapat meraih capaian tertinggi pada pemilu legislatif.

Analisis yang digunakan oleh penulis adalah modal politik, modal sosial, dan modal ekonomi. Modal politik menurut Kimberly Casey (2008) yaitu jumlah dari kombinasi jenis modal lain untuk tindakan politik atau pengambilan investasi modal politik yang dikembalikan ke dalam sistem produksi (reinvestasi). Modal politik dapat dikatakan sebagai modal dasar bagi calon legislatif dalam pemilu legislatif. Menurut Sørensen dan Torfing (2003) modal politik mengacu pada kekuasaan individu untuk bertindak secara politis yang dihasilkan melalui partisipasi dalam proses politik yang interaktif. Sehingga seorang calon legislatif harus memiliki dukungan politik melalui partai politik agar dapat terpilih dalam pemilihan legislatif. Selain dukungan dari partai politik, modal politik berupa dukungan dari elit politik juga dapat mempengaruhi keterpilihan calon legislatif.

Kemudian, modal lain yang juga penting dalam sebuah pemilu legislatif yaitu modal sosial. Modal sosial yang dimaksud pada penelitian ini adalah modal yang dimiliki oleh figur calon legislatif karena figur dan jaringan yang dimiliki sehingga adanya kepercayaan dari masyarakat yang mendukung calon legislatif tersebut. Robert Putnam (1993) yang menyatakan bahwa modal sosial adalah suatu mutual trust antara anggota masyarakat dan masyarakat terhadap pemimpinnya. Pendapat ini mengandung pengertian diperlukan ikatan atau jaringan sosial yang ada dalam masyarakat, dan norma yang mendorong produktivitas. Dalam pemilu legislatif, selain modal politik dan modal sosial, seorang calon legislatif juga harus memiliki modal ekonomi dengan tujuan untuk memenuhi ongkos politik yang dibutuhkan selama proses kampanye. Menurut Bourdieu modal ekonomi adalah akar dari semua jenis 
modal lain (Bourdieu, 1986: 252). Modal ekonomi merujuk pada dukungan dana atau finansial berupa uang baik berasal dari sendiri ataupun partai politik dan pihak-pihak lainnya. Dukungan ekonomi yang dibutuhkan oleh calon legislatif dalam pemilu legislatif tidak hanya berasal dari dirinya sendiri atau sumber dana pribadi saja, namun juga berasal dari aktor-aktor ekonomi atau donatur lainnya.

Pendekatan tiga modal ini digunakan karena Ima Mahdiah berkompetisi di Provinsi DKI Jakarta, suatu daerah yang memiliki kondisi politik, sosial, dan ekonomi yang cukup berbeda dibandingkan dengan daerah lain di Indonesia. Secara politik, Provinsi DKI Jakarta merupakan daerah yang dinamis. Sejak tahun 2007-2017, Gubernur DKI Jakarta hanya menjabat selama satu atau kurang dari satu periode. Selain itu pemenang pemilu legislatif berganti terus. Dari sudut pandang sosial, Provinsi DKI Jakarta adalah daerah multi etnis, multi budaya dan merupakan daerah urban. Berdasarkan data Badan Pusat Statistik (BPS) 2010, terdapat beragam etnis penduduk Provinsi DKI Jakarta antara lain Jawa, Betawi, Sunda, Tionghoa, Batak, Minangkabau, Melayu, Bugis, Madura, Banten, dan lain-lain.

Disamping itu, Jakarta juga merupakan pusat bisnis dan ekonomi Indonesia, yang ditandai dengan posisi Jakarta sebagai daerah dengan Produk Domestik Regional Bruto (PDRB) tertinggi di Indonesia, dengan jumlah 2.599,17 triliun rupiah (Kementerian Keuangan, 2019). Sebagian besar perusahaan swasta nasional dan BUMN juga menempatkan kantor pusatnya di Provinsi DKI Jakarta. Provinsi DKI Jakarta juga merupakan daerah dengan populasi dan kepadatan tertinggi di Indonesia. Dengan demikian, faktor ekonomi tidak dapat diabaikan dalam menganalisis penyebab seseorang terpilih dalam pemilihan legislatif di Provinsi DKI Jakarta. Penggunaan ketiga modal ini sebagai alat analisis diharapkan mampu menjelaskan keterpilihan seseorang pada pemilu legislatif secara komprehensif dan mencerminkan kompleksitas Jakarta sebagai suatu wilayah pemilihan.

\section{Modal Politik Calon Legislatif Perempuan Pemula}

Dalam pelaksanaan pemilu legislatif, calon legislatif perempuan pemula memerlukan dukungan politik dari partai politik untuk dapat dicalonkan. Adanya dukungan dari partai politik merupakan modal politik yang kuat untuk dapat memenangkan pemilu. Menurut Field (2003) modal politik merupakan pendayagunaan keseluruhan jenis modal yang dimiliki oleh seorang pelaku politik atau sebuah lembaga politik untuk menghasilkan tindakan politik yang menguntungkan atau memperkuat posisi pelaku politik atau lembaga politik bersangkutan. Selain dukungan partai, dukungan elit politik yang cukup berpengaruh juga dibutuhkan untuk dapat mendukung seorang calon legislatif dalam pemilu.

Modal politik yang dimiliki oleh Ima Mahdiah berasal dari partai yang mengusungnya, yaitu PDIP. Melalui PDIP, Ima bertemu dengan para elit partai yang juga memberinya dukungan pada pemilu legislatif DPRD Provinsi DKI Jakarta tahun 2019. Dalam wawancaranya, Ima menyatakan mendapatkan dukungan dari ketua DPD PDIP DKI Jakarta, Adi Wijaya untuk mencalonkan diri pada pemilu legislatif tahun 2019 melalui dapil DKI Jakarta X yang meliputi wilayah Kota Administrasi Jakarta Barat (Kec. Taman Sari, Kec. Grogol Petamburan, Kec. Palmerah, Kec. Kebon Jeruk, Kec. Kembangan). Dalam pencalonannya, nomor urut dan dapil telah diatur oleh partai politik dan ketua DPD, sehingga ketika mencalonkan diri pada pemilu legislatif, Ima Mahdiah mendapatkan nomor urut 8 dan di tempatkan di dapil DKI Jakarta X. Meskipun demikian, menurut Ima nomor urut tidak berpengaruh karena sistemnya adalah suara terbanyak, sehingga fokus Ima adalah dapat membuat masyarakat di dapilnya memilih dirinya (Wawancara, 8 Februari 2021).

\section{Modal Sosial Calon Legislatif Perempuan Pemula}

Modal sosial merupakan hubungan sosial yang terjalin dalam kehidupan sehari-hari warga masyarakat, dimana hubungan sosial mencerminkan hasil interaksi sosial dalam waktu yang relatif lama sehingga menghasilkan jaringan, pola kerjasama, pertukaran sosial, saling percaya termasuk norma dan nilai yang mendasari hubungan sosial tersebut. Robert Putnam (1993) yang menyatakan bahwa modal sosial adalah suatu mutual trust antara anggota masyarakat dan masyarakat terhadap pemimpinnya.

Modal sosial yang dimiliki Ima Mahdiah mencakup jaringan pendukung, jaringan relawan, dan posisi Ima sendiri sebagai orang yang lahir dan besar di Jakarta. Jaringan pendukung diperoleh Ima dari pengalamannya sebagai Staf Basuki. Pengalaman kerja dengan Basuki juga membuat Ima mengenal relawan-relawan yang sebelumnya adalah relawan Basuki. Terakhir, dengan posisinya yang lahir dan besar di Jakarta, Ima relatif mengenal karakter dan komposisi penduduk Jakarta yang majemuk dan memiliki beragam kepentingan.

Jaringan pendukung Ima kebanyakan terbangun dari jaringan pendukung Basuki. Hal ini tidak 
terlepas dari fakta bahwa dapil DKI Jakarta X tempat Ima memenangkan pemilu legislatif merupakan basis pendukung Basuki (KPUD DKI Jakarta, 2017). Selain itu, hubungan sosial antara Ima dan konstituen di dapil juga terbangun melalui penugasannya semasa bekerja dengan Basuki untuk mengetahui dan menyelesaikan permasalahan di daerah tersebut. Dalam penugasan ini Ima kerap bertemu dengan masyarakat dari berbagai lapisan, sekaligus menjalin hubungan dengan tokoh dan kelompok masyarakat di dapil DKI Jakarta X. Selain itu, jaringan-jaringan pendukung Basuki juga dimanfaatkan Ima melalui kampanyenya yang menyertakan foto Basuki ke dalam spanduk dan poster.

Karakteristik dapil DKI Jakarta X dan Provinsi DKI Jakarta pada umumnya yang memiliki jumlah dan kepadatan penduduk yang tinggi mengharuskan calon legislatif memiliki tim sukses atau relawan yang dapat menjangkau mayoritas penduduk. Ima Mahdiah memperoleh bantuan relawan sebagai tim sukses. Relawan ini dikenal dan direkrutnya dari basis relawan yang tergabung di tim Kampanye Basuki di Pemilihan Kepala Daerah tahun 2012 dan 2017. Relawan ini membantu Ima karena hubungan sosial yang telah terjalin selama bekerja dengan Basuki. Disamping itu, pengalaman bekerja sama dan simpati yang sama terhadap Basuki juga membantu membangun soliditas tim sukses Ima selama masa kampanye. Hal ini berbeda dengan tim sukses atau relawan yang berasal dari partai, yang membantu karena penugasan dari pengurus pusat atau pengurus daerah partai.

\section{Modal Ekonomi Calon Legislatif Perempuan}

Sistem pemilu terbuka dengan suara terbanyak membuat setiap calon legislatif perempuan harus menyiapkan modal ekonomi yang sangat besar dengan tujuan untuk memenuhi ongkos politik yang dibutuhkan selama proses kampanye. Misalnya, keperluan membuat spanduk sebagai alat peraga kampanye, membayar relawan untuk membantu mengawasi jalannya pemilu, dan lain-lain. Terlebih, sebagai calon legislatif perempuan pemula, Ima harus melakukan kampanye untuk mempromosikan dirinya kepada masyarakat di dapil DKI Jakarta X. Dalam hal ini, calon legislatif perempuan pemula dituntut untuk dapat mengenalkan dirinya agar dapat mempengaruhi pilihan masyarakat. Mayoritas calon legislatif menggunakan modal ekonomi untuk memperkuat modal sosial dan modal politik. Modal ekonomi menjadi modal pendukung agar masyarakat benar- benar memilihnya.

Dalam pemilu legislatif DPRD DKI Jakarta tahun 2019, modal ekonomi Ima sebagian besar berasal dari dana pribadi dan dana dari relawan-relawan Basuki. Selain itu, Ima juga menerima dana dari PDIP, namun jumlahnya tidak sebesar dana yang diperoleh dari penggalangan dan relawan-relawan Basuki. Ima menyebutkan, sebagian besar dana ini digunakan untuk kampanye tatap muka dan pengadaan alat peraga kampanye seperti spanduk, poster, dan lainnya. Hal ini penting untuk daerah dengan jumlah penduduk yang padat dan memiliki kesibukan tinggi seperti Jakarta, dimana tidak semua penduduk dapat hadir di kampanye tatap muka dan sebagian besar hanya mengenal calon legislatif dari materi kampanye di ruang terbuka. Selain itu, dana ini juga digunakan untuk memberikan insentif kepada tim kampanye dan saksi, sebagaimana pula dilakukan sebagian besar calon legislatif lainnya baik di Provinsi DKI Jakarta maupun di seluruh Indonesia.

\section{KESIMPULAN}

Modal politik, modal sosial, dan modal ekonomi dapat berasal dari berbagai sumber. Pada keterpilihan Ima Mahdiah, modal politik berasal dari partai politik yang mengusungnya, yaitu PDIP. Disamping itu, posisi PDIP sebagai partai pemenang pemilu legislatif sebelumnya juga memiliki pengaruh yang tidak dapat dikesampingkan. Sedangkan pengalaman Ima terjun ke masyarakat dan jaringan yang diperolehnya selama bekerja di tim Basuki menjadi sumber modal sosialnya. Adapun modal ekonomi Ima bersumber dari pendanaan relawan Basuki dan pendanaan parpol. Mengingat latar belakang Ima yang tidak berasal dari dunia bisnis (maupun dirinya yang tidak menjalin hubungan erat dengan pebisnis), modal ekonomi memiliki posisi yang tidak terlalu signifikan dibandingkan dengan modal politik dan sosial. Meskipun demikian, modal ekonomi membantu Ima memenuhi aspek praktis kampanye seperti pendanaan kampanye, relawan, dan saksi. Dapat disimpulkan dari artikel ini, bahwa akses dan penguasaan terhadap modal politik dan modal sosial merupakan aspek penting kemenangan seorang calon legislatif perempuan pemula. Adapun modal ekonomi dapat dianggap sebagai modal penunjang dan penguat modal politik dan modal sosial.

\section{REFERENSI}

Ancok, Djamaludin., 2003, Modal Sosial dan Kualitas Masyarakat. Jurnal Pemikiran dan Penelitian 
Psikologi, Vol. 8(15): 4-14

Baharuddin, T. dan T. Purwaningsih., 2017, Modalitas Calon Bupati dalam Pemilihan Umum Kepala Daerah Tahun 2015, Journal of Governance and Public Policy, Vol. 4(1): 205-237

Bourdieu, Pierre., 1986, The Forms of Capital, dalam Richardson, J.G. (ed), Handbook of Theory and Research for The Sociology of Education, New York: Greenwood Press

Casey, K. L., 2008, Defining Political Capital: A Reconsideration of Bourdieu's Interconvertibility Theory, Paper Presented at the Illinois State University Conference for Student of Political Science, University of Missouri St.Louis

Field, J., 2003, Social Capital, London: Routledge

Kambo, G. A., 2017, Penguatan Identitas Perempuan dalam Pemilihan Kepala Daerah, The Politics: Jurnal Magister Ilmu Politik Universitas Hasanuddin, Vol. 3(1): 1-16

Kementerian Keuangan, 2019, PDRB Atas Dasar Harga Berlaku 34 Provinsi di Indonesia (2018), Diakses dari databoks.katadata.co.id

Moleong, L. J., 2012, Metodologi Penelitian Kualitatif(Ed), Bandung: PT. Remaja Rosdakarya

Mutmainnah, 2017, Keterpilihan Calon Legislatif Perempuan Partai Golkar Pada Pemilihan Umum Legislatif Tahun 2014 di Kabupaten Sidrap, The POLITICS: Jurnal Magister Ilmu Politik Universitas Hasanuddin, Vol. 3(2): 94-107

Nurmalasari, D. dan A. G. Karim, M.A., 2010, Modalitas perempuan dalam kontestasi politik local Studi kasus pada caleg perempuan dalam Pemilu 2009 di Kabupaten Indramayu Jawa Barat, Tesis, Yogyakarta: Universitas Gadjah Mada

Putnam, R. D., 1993, Making Democracy Work: Civic Traditions in Modern Italy, Princeton: Princeton University Press

Robinson, K., 2000, "Indonesian Women: from Orde Baru to Reformasi" dalam Women in Asia, Tradition, Modernity and Globalisation, diedit oleh Louise Edwards and Mina Roces, London \& New York: Routledge, 2010: 139-168

Sirait, M. Z., P. A. Noak., dan M. A. Azhar., 2020, Modalitas dalam Keterpilihan Kandidat Pada Pemilu Legislatif 2014, E-Journal Politica, Vol. 1(2): 1-10

Sørensen, E. dan J. Torfing., 2003, Network Politics, Political Capital, and Democracy, International Journal of Public Administration, Vol. 26(6): 609-634

Squires, J., 1999, Gender In Political Theory, Cambridge: Polity Press 